\title{
Time spent with food and nonfood incentives as a function of food deprivation
}

\author{
James Allison and Maria Rocha e Silva ${ }^{\prime}$ \\ INDIANA UNIVERSITY
}

\begin{abstract}
Rats were presented with pairs of the following incentives at 0.11 , and $22 \mathrm{hr}$. of food deprivation: food, plaything, and rat. Time spent with food increased up to $11 \mathrm{hr}$., but time spent with plaything vs. rat was independent of food deprivation. Ss preferred plaything to rat, food to rat, and food to plaything, with one exception: nondeprived Ss preferred plaything to food.

\section{Problem}

Rats deprived of food for $22 \mathrm{hr}$. show stable individual differences in proportion of time spent with food rather than a plaything or another rat. In addition, this measure (F) shows various functional similarities to hours of food deprivation, e. g., it is directly related to instrumental performance for food in a $\mathrm{T}$-maze and a straight alley (Allison, 1964). To study more directly the relationship between $\mathrm{F}$ and food deprivation the present experiment measured $\mathrm{F}$ at 0,11 , and $22 \mathrm{hr}$. of deprivation.

Another objective was to study the effect of food deprivation upon time spent with relevant and irrelevant incentives. The concept of irrelevant incentive, as employed here, implies that time spent with a given incentive is not affected by variations in a given drive. It was expected that time spent with food vs. rat, and food vs. plaything, would vary with food deprivation, but time spent with plaything vs. rat would not.

If $S$ spends more time with incentive $X$ than incentive $\mathrm{Y}, \mathrm{S}$ is said to prefer $\mathrm{X}$ to $\mathrm{Y}$. In the previous experiment Ss generally preferred food to rat, food to plaything, and plaything to rat. The present experiment was designed to determine whether such preferences could be reversed by manipulating hours of deprivation.

\section{Method}

The Ss were 72 male hooded rats, 74-84 days old.

Three wooden U-shaped enclosures were used to present the incentives. Each enclosure was 7.5 in high. and consisted of two 8 in by 12 in chambers (the arms of the U) connected by an alley 4 in wide and 8 in long (the base of the U). Each enclosure had a hinged plexiglass top covered with translucent waxed paper.

Each chamber offered one of three incentives: a metal trough attached to a wall, filled with wet mash; a plaything consisting of a hardware-cloth step with a 3.5 in tread, 4.5 in wide and 2 in high, attached to a wall; or a male rat which $\mathrm{S}$ could view through a plexiglass wall. In the above description, "wall" refers to the inside wall of the U. One enclosure presented food vs. plaything, another food vs. rat, and the third plaything vs. rat. The S's crossings from one chamber to the other were monitored by means of a floating metal runway pivoted at the center of the alley. An event marker recorded the amount of time $\mathrm{S}$ spent in each chamber.

The Ss were assigned to three groups of 24 each, matched by body weight, and were housed three to a cage. They were fed wet mash ad $1 \mathrm{ib} 2 \mathrm{hr}$. daily, with water always available, for 6-16 days prior to the test. On each of the six days preceding the test Ss were handled and allowed to explore each enclosure for $1 \mathrm{~min}$., with the incentives removed. The 0,11 , and $22 \mathrm{hr}$. groups were fed at 8-10 am, 9-11 pm, and 10-12 am respectively, and were tested once at 10-12 am.

Testing was conducted in platoons of nine and squads of three, where each squad included one $\mathrm{S}$ from each drive condition. Members of a given squad were tested simultaneously, one in each enclosure. After $10 \mathrm{~min}$. they were removed and another squad was brought in. This procedure was repeated until each of the nine Ss had spent $10 \mathrm{~min}$. in each enclosure. Between its three 10-min. sessions $\mathrm{S}$ waited in its home cage for approximately $25 \mathrm{~min}$.

There were six possible orders in which $\mathrm{S}$ could be presented with the three pairs of incentives, and four $\mathrm{Ss}$ in each drive condition received each presentation order. Of these, two Ss received two intial placements in a food chamber and one in a rat chamber, while the other two Ss were placed twice in a play chamber and once in a rat chamber.

\section{Results}

Proportion of time spent with food rather than plaything or rat (F) increased up to $11 \mathrm{hr}$. of deprivation, then leveled off $(F=32.69 ; \mathrm{df}=2 / 36 ; \mathrm{p}<.001)$. The means were $.49, .84$, and .83 . Tukey tests using the $1 \%$ confidence interval showed significant differences only between gp. 0 and 11 , and 0 and 22 .

To evaluate the effect of food deprivation upon time spent with relevant and irrelevant incentives, further analyses were carried out on the following measures: proportion of time spent with food rather than rat (FR), food rather than plaything (FP), and plaything rather than rat (PR). The overall means for FR, FP, and PR were $.78, .66$, and .54 respectively $(F=18.53$; $\mathrm{df}=2 / 72$; $\mathrm{p}<.001)$. Measures FR and FP increased up to $11 \mathrm{hr}$. of deprivation, then leveled off, while PR did not vary with deprivation (see Fig. 1). In line with this finding, analysis of variance showed a significant Drive $x$ Pair interaction $(\mathrm{F}=8.37 ; \mathrm{df}=4 / 72 ; \mathrm{p}<.001)$. Trend analysis showed significant linear and quadratic trends for FR and FP $(p<.01)$, while for PR neither trend was 


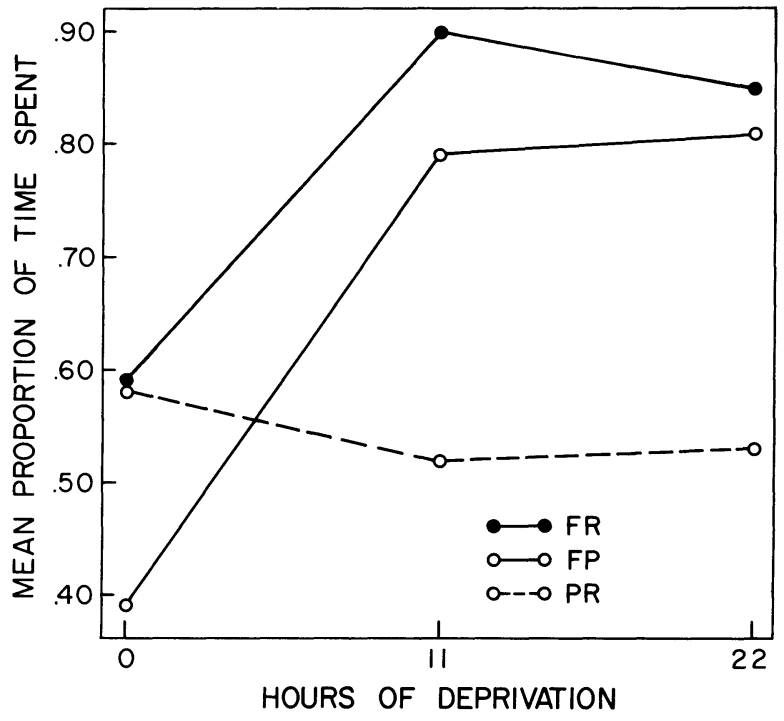

Fig. 1. Proportion of time spent with food rather than rat (FR), food rather than plaything (FP), and plaything rather than rat (PR) as a function of food deprivation.

significant $(F<1)$. Measures $F R$ and FP appeared to converge as deprivation increased, but this was not statistically significant.

Figure 1 indicates that gp. 22 preferred food to rat, food to plaything, and plaything to rat, in agreement with previous results. Two-tailed binomial tests were significant at the .1\% level for FR and FP, but were not significant for PR $(p=.31)$. Strictly comparable results were obtained for gp. 11. Group 0 differed from the others in preferring plaything to food $(p=.06)$, and in two other respects: its preference for food over rat was not significant $(p=.21)$, but the preference for plaything over rat was $(p=.02)$.

\section{Discussion}

Rats offered a choice between food and nonfood incentives spend an increasing proportion of time with food as deprivation increases from 0 to $11 \mathrm{hr}$. Food deprivation does not affect time spent with nonfood incentives. Apparently the time-spent method offers a promising means of determining whether a given incentive is relevant or irrelevant with respect to a given drive.

Rats tested at 11 and $22 \mathrm{hr}$. prefer food to plaything, but those tested at $0 \mathrm{hr}$. prefer plaything to food. This suggests that for most nondeprived rats a plaything may provide more effective reinforcement than a food reward -an hypothesis consistent with Premack's (1959) theory of reinforcement. Powerful methods of increasing the incentive value of rat and plaything are notimmediately apparent, but it does seem likely that the value of rat can be decreased by rearing $\mathrm{Ss}$ in social isolation (Angermeier, 1960).

\section{Referenees}

ALLISON, J. Strength of preference for food, magnitude of food reward, and performance in instrumental conditioning. J. comp. physiol. Psychol., 1964, 57, 217-223.

ANGFRMEIFR, W. F. Some basic aspects of social reinforcements in albino rats. J. comp. physiol. Psychol., 1960, 53, 364-367. PRFMACK, D. Toward empirical behavior laws: I. Positive reinforcement. Psychol. Rev., 1959, 66, 219-233.

Note

1. The authors thank Lois Loats for her assistance in collecting the data. Her participation was made possible by an Undergraduate Research Participation Grant from the National Science Foundation. 